\title{
Phytogeographical Study of the Family Orobanchaceae in Kurdistan Region-Iraq
}

\author{
Sirwan Hassan Salih
}

Biology Department, College of Education, University of Garmian, Kalar, Kurdistan Region, Iraq Email: herash1966@yahoo.com

\begin{abstract}
This study included a comprehensive survey of the north and northeast districts of Iraq, the ecology and geographical distribution of the Orobanchaceae species available in Iraqi Kurdistan regions in Duhok, Arbil and Sulaimani governorates were investigated, based on data collected from different sources, geographical distribution was made by the aid of prepared maps, ecological notes were pointed out regarding the different environmental types, species distribution of two genera (Orobanche L. and Phelypaea L.) of the family and two endemic species (O. ovata and O. singarensis) has been recorded, as well it was noted that the O. aegyptiaca Pers. is the most widely distributed specie (common species) and Phelypaea coccinea was the rare species.
\end{abstract}

Keywords: Phytogeography, Orobanchaceae, Kurdistan region-Iraq.

\section{Introduction}

Orobanchaceae (Broomrape family) widely distributed in warm and temperate area, about $90 \%$ of their species are old world natives and only about $10 \%$ of the species occur in the cold or hot regions (Thieret, 1971). It is obviously known that the plant spreading influenced by geographical and environmental conditions therefore the Orobanchaceae species show a high variation in their distribution in different environmental conditions. Ecological and geographical distribution of plants are clearly much relevance to plant taxonomy because each species or groups of plants are with a certain pattern of distribution which is one aspect of its definition. The aims of plant 
geography are to ascertain the essential features and recurrent patterns of the special distribution of plants and to discover their fundamental causes, which lie partly in their ecology. The data on geographical distribution of this study was obtained from some herbarial specimens that have been previously reported, literatures and personal field trip.

\section{Materials and Methods:}

The materials that were used as a data source are herbarial specimens(table 1), labels of major Iraqi herbaria (table 1), personal field trips in districts of MAM, MRO, MSU, FAR, FKI and FPF (figure 1,2), literatures and Iraqi plants lists that published by: Handle Mazzetti (1910); Zohary (1946); Blackelock (91949); Al-Rawi (1964); Khalaf (1980); Ridda and Daoud (1982); Faris (1983) and some Floras such as: Flora of Syria. Pal,. Sin. (Post, 1933); Flora Iranica (Parsa, 1949); Flora Lowland of Iraq (Rechinger, 1964); Flora Iranica (Rechinger, 1964); Flora of Turkey (Davis and et al, 1982). The altitudes were measured by altimeter while the taxonomic terminology were derived from Lawrence (991951); Guest, 1966; Al-Mussawi (1987); Al-Katib (1988). Geographical distribution was made by aid of prepared maps (figure 3,4,5) and it is focused on Iraqi Kurdistan regions (figure 2),

\section{Results and Discussion:}

\subsection{Ecology and Geographical Distribution:}

The results of this study showed that the species of two genera (Orobanche L. and Phelypaea L.) of the family Orobanchaceae in Iraq are distributed in Kurdistan region, three species of Orobanche are newly recorded for Iraq and species Orobanche mutelii is newly recorded for Kurdistan, so there are 12 species belongs to two genera distributed in Kurdistan region, species with large population as O. aegyptiaca due to it is grow on both wild and cultivated plants, while some species of O. crenata, O. kurdica and $O$. ovata are sparsely distributed, species Phelypaea coccinea and O. arenaria are rare in their distribution. 
The Orobanchaceae species are obligatory parasite plants therefore the geographical distribution depended directly on the distribution of their hosts (wild and cultivated plants), $O$. aegyptiaca \{figure 3, table 2 \} is the most widely distributed species extended in different environments and laces from Kifri (FKI), south of surveyed regions to Kany Massy near Zakho (MAM) north of included surveying regions, so the O. aegyptiaca was found in all districts which included in this investigation, it's altitude range 200$1700 \mathrm{~m} ; O$. anatolica \{figure 4, table 2 \} was dominated among examined species in Piramagrun and Azmer mountain (MSU), it's altitude range 900-1800m in rocky mountain; $O$. arenaria was newly recorded ffigure 4, table 2 \} scarcely distributed in Piramagrun mountain (MSU), 1250-1550m altitude, it parasite on wild plants; $O$. coelestis (figure 5, table 2) spread in Piramagrun mountain (MSU) and Arbil (MRO), 750-1650 m alt., in rocky mountain; O. crenata (fig. 4, tab. 2) distributed in Duhok (MAM) and Piramagrun mountain (MSU), 900-1800m, parasites on wild plants; $O$. kurdica \{figure 5, table 2\} distribute with high density in Zakho and Duhok (MAM), Chuwarta and Piramagrun mountain (MSU), 900-1800m alt.; O. minor (new record) ) (figure 4, table 2) scattered in Duhok (MAM) and Sartaky Bamou mountain (FPF), $1100-1750 \mathrm{~m}$ alt., it is only parasites on wild plants in rocky mountain; O. mutelii (newly recorded for Kurdistan) (figure 4, table 2) distributes in Kalar (FPF) in semi desert habitat, 200-450m, parasites on wild plants; O. ovata (endemic species) \{figure 4, table 2 \} distributed in Piramagrun mountain (MSU) and Sere Hassan Beg (MRO), 15002000m, in rocky mountain, parasites on wild plants; O. ramosa (newly recorded) (figure 5, table 2) distributed in Zakho (MAM) and Erbil (MRO), 600-850 m, in hill, plateaus and Rocky Mountains, parasite on both wild and cultivated plants; $O$. singarensis (endemic species) (figure 5, table 2) distribute in Chuwarta and Piramagrun mountain (MSU) and Kalar (FPF) in addition to Sinjar mountain (FJS), 200-900m, it's habitats are plains and rocky mountains; $P$. coccinea (rare species) (figure 5, table 2)distribute only in a specific small area in Piramagrun mountain (MSU) 1500-2000m, parasite on wild plants, on the other hand the species O. aegyptiaca, O. coelestis and O. mutelii are 
distributes in another regions in mid and south of Iraq (according to the labels of herbarial specimens and of Iraqi plants lists) which are entirely different from their habitats with the habitats of Kurdistan in (climate, altitude, soil type and hosts). As well the results of (figure 6,7) showed that the MSU district are the most districts where the species are spread (9 species) and the FKI is the less districts ( 1 species) and the most common species O. aegyptiaca are distributed in all six included districts and species of $P$. coccinea, O. mutelii, $O$. crenata and $O$. anatolica are less distributed species (1 district). The density of populations of studied species depended on densities of their hosts populations and somewhat on germination conditions and environments.

some of these species parasite on cultivated plants and others on wild plants while some species on both of them, likewise these species may be disappeared in their original places when their hosts are absent, consequently may cause to change the geographical distribution of these species from time to time,

Table (1) Herbaria which used their specimens during the study abbreviation follow Holmgren \&

Keuken 1989

\begin{tabular}{|l|l|}
\hline BAG & Baghdad Iraq. College of Agriculture \\
\hline BAH & Baghdad Iraq. National herbarium of Iraq \\
\hline BUH & Baghdad, the university herbarium, college of Science, dept. of Biology \\
\hline BUNH & Baghdad, Iraq. Natural history research center of Education University of Baghdad \\
\hline BUE & Baghdad, Iraq. Dep. of biology, college of Education, University of Baghdad \\
\hline SUH (ASUH) & Arbil, Iraq. College of Science, University of Salahaddin \\
\hline ESUH & Erbil, Iraq. College of Education university of Salahaddin \\
\hline MSUH & Mosul, Iraq. College of Science, University of Mosul \\
\hline
\end{tabular}




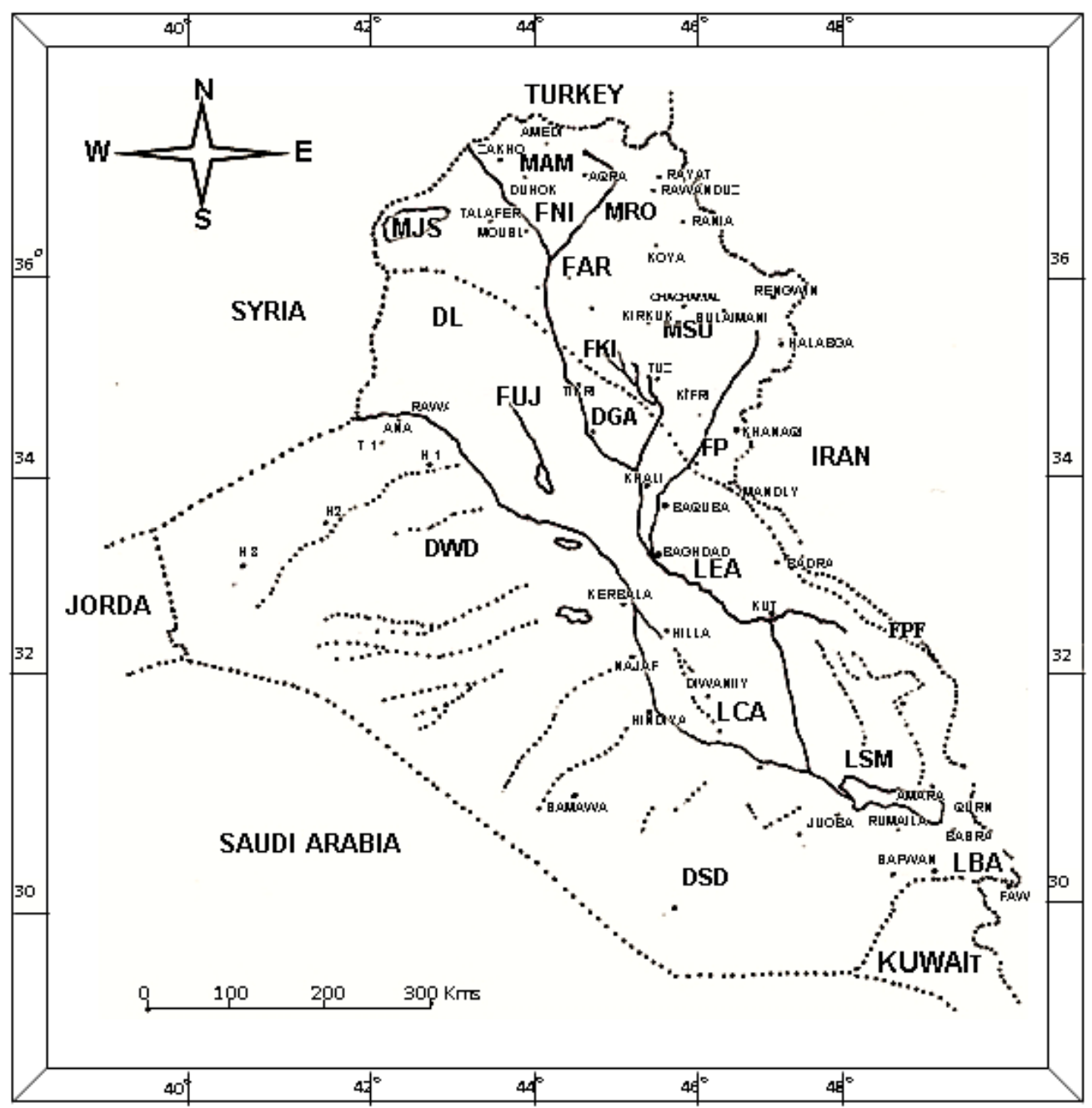

Figure (1) Physiographic regions and Districts map of Iraq

M - MOUNTAIN

REGION

MAM - Amadiya District

MRO - Rowanduz District

MSU - Sulaimani District

MJS - Jabal Singar District
F - UPPER PLAINS AND

FOOTHILLS REGION

FUJ- Upper Jaziera District

FNI- Nieneveh District

FAR- Arbil District

FKI- Kirkuk District

FPF- Persian District 
D - LOWER PLATEAU L - LOWER MESOPOTAMIAN

\section{REGION}

DLJ - Lower Jaziera

District

DGA- Ghurfa - Adhaim

District

DWD - Western Desert

District

DSD- Southern Desert

District

\section{REGIO}

LEA- Eastern Alluvial Plain District

LCA- Central Alluvial Plain District

LSM- Southern Marsh District

LBA- Basra Estuarine District

Physiographic regions and districts of Iraq.

(Physiographic is the abbreviation and details of Iraqi geographical districts)

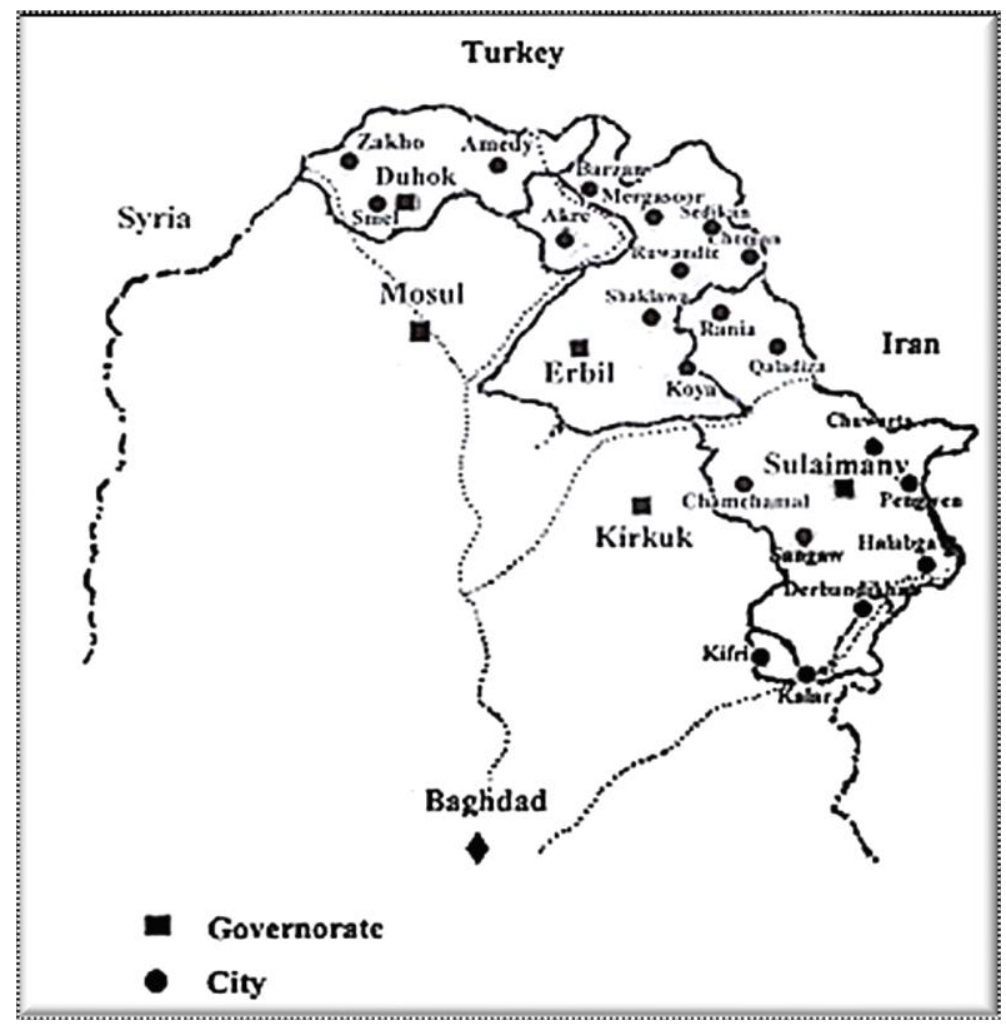

Figure (2), surveyed regions map 


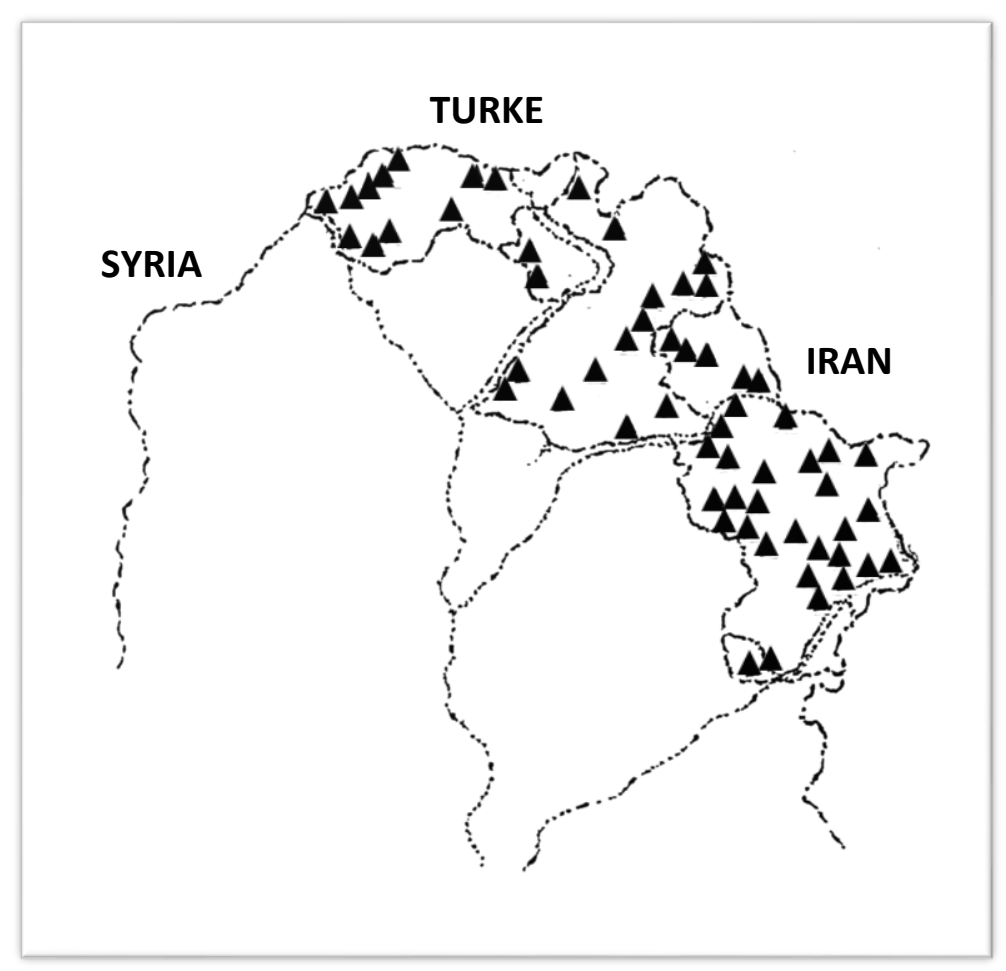

Figure (3) Distribution map of: O. aegyptiaca

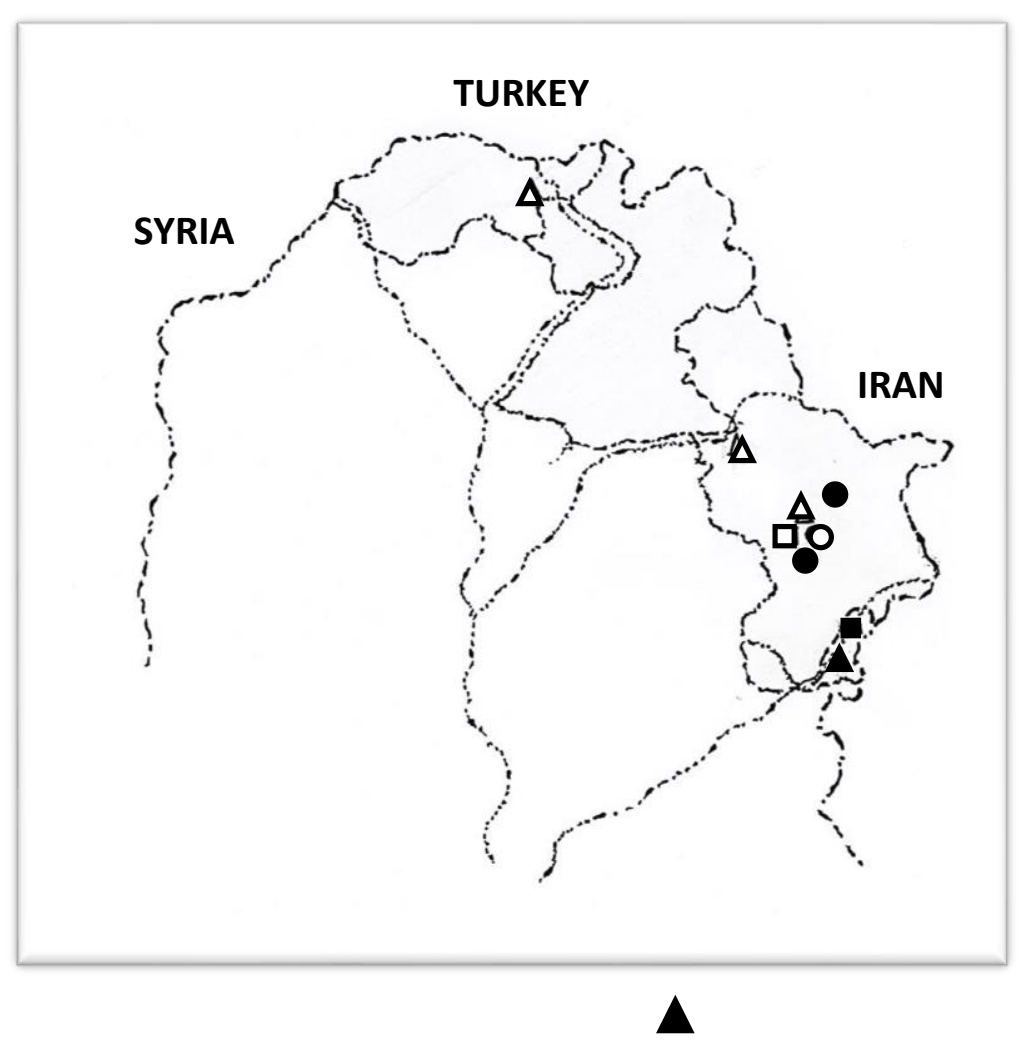


Figure (4) Distribution map of:

$\begin{array}{llll}\text { - O. ovata } & \Delta & \text { O. mutelii } \bigcirc & \text { O. arenaria } \\ \text { O. minor } & \Delta & \text { O. crenata } & \text { O. anatolica }\end{array}$

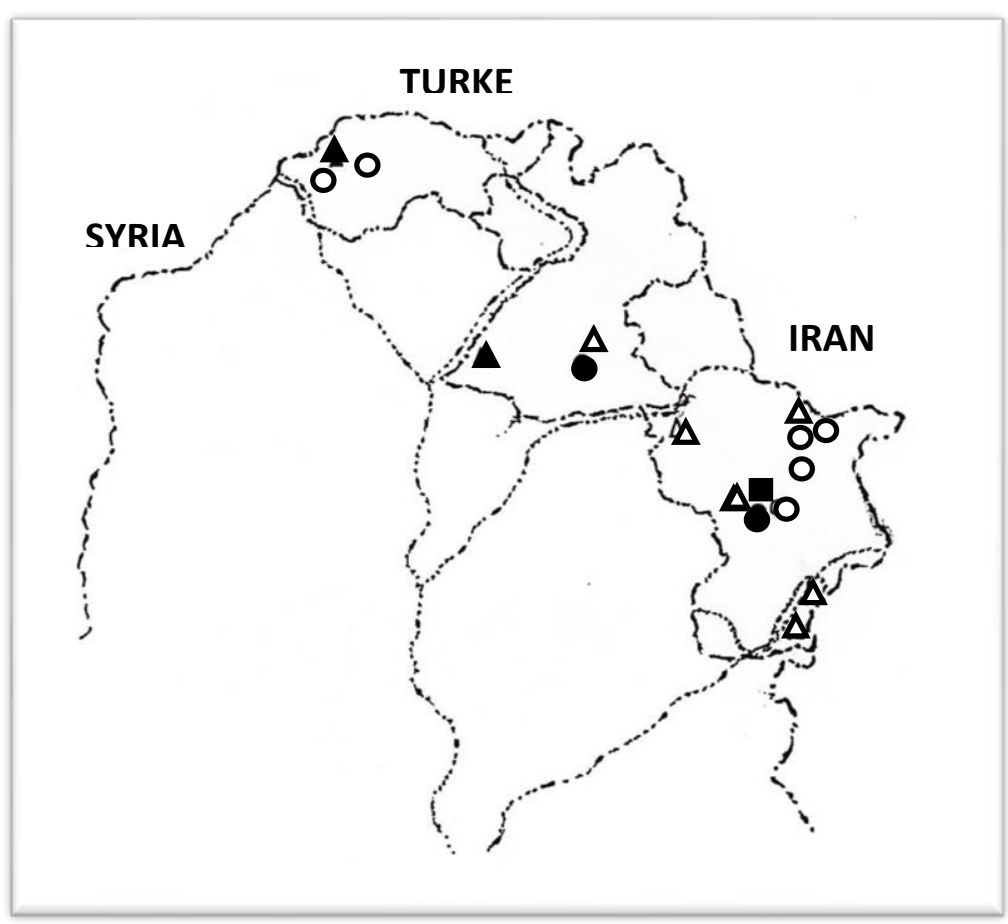

Figure (5) Distribution map of:
$\triangle \quad$ O. singarensis
P. coccinea O. kurdica
O. ramosa
O. coelestis 


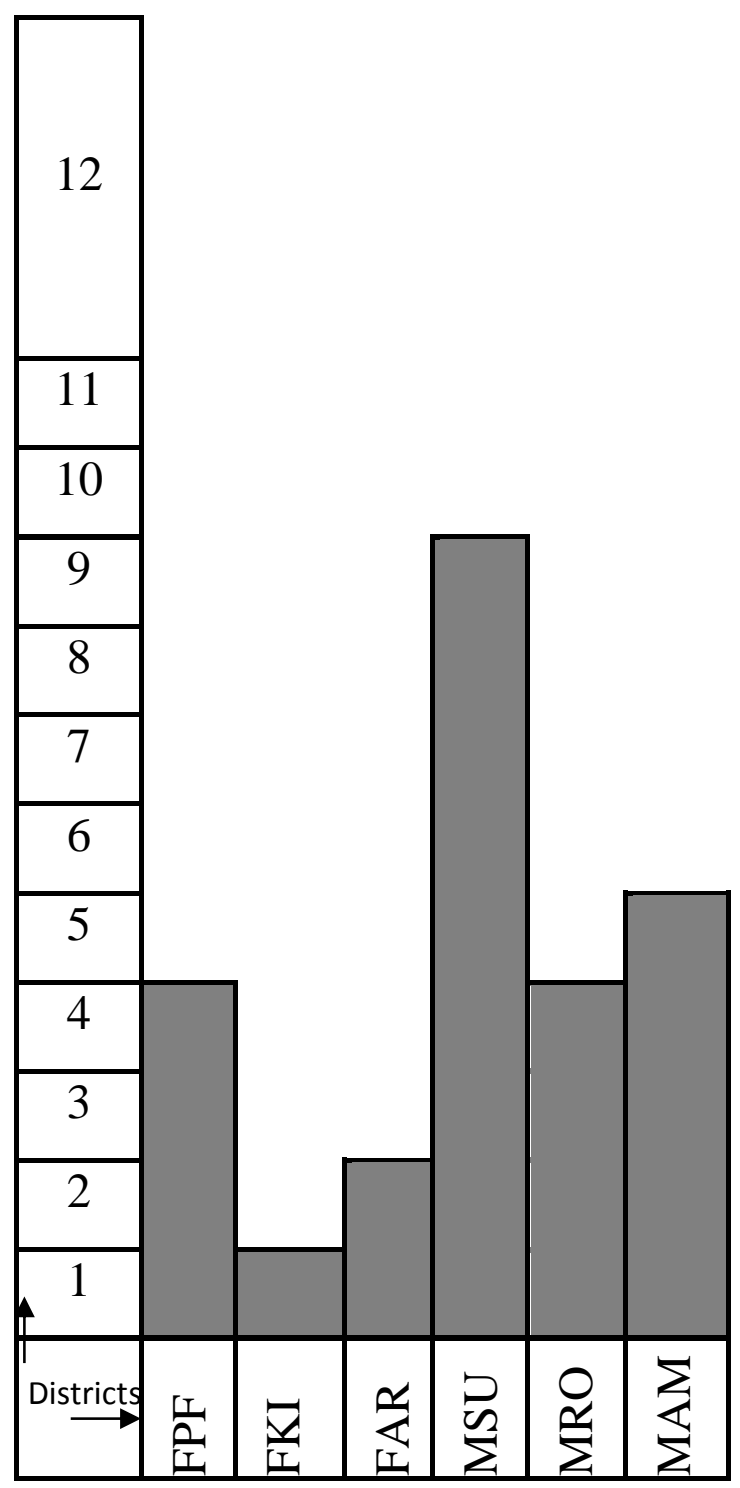

Figure (6) Number of species deployed in each district. 


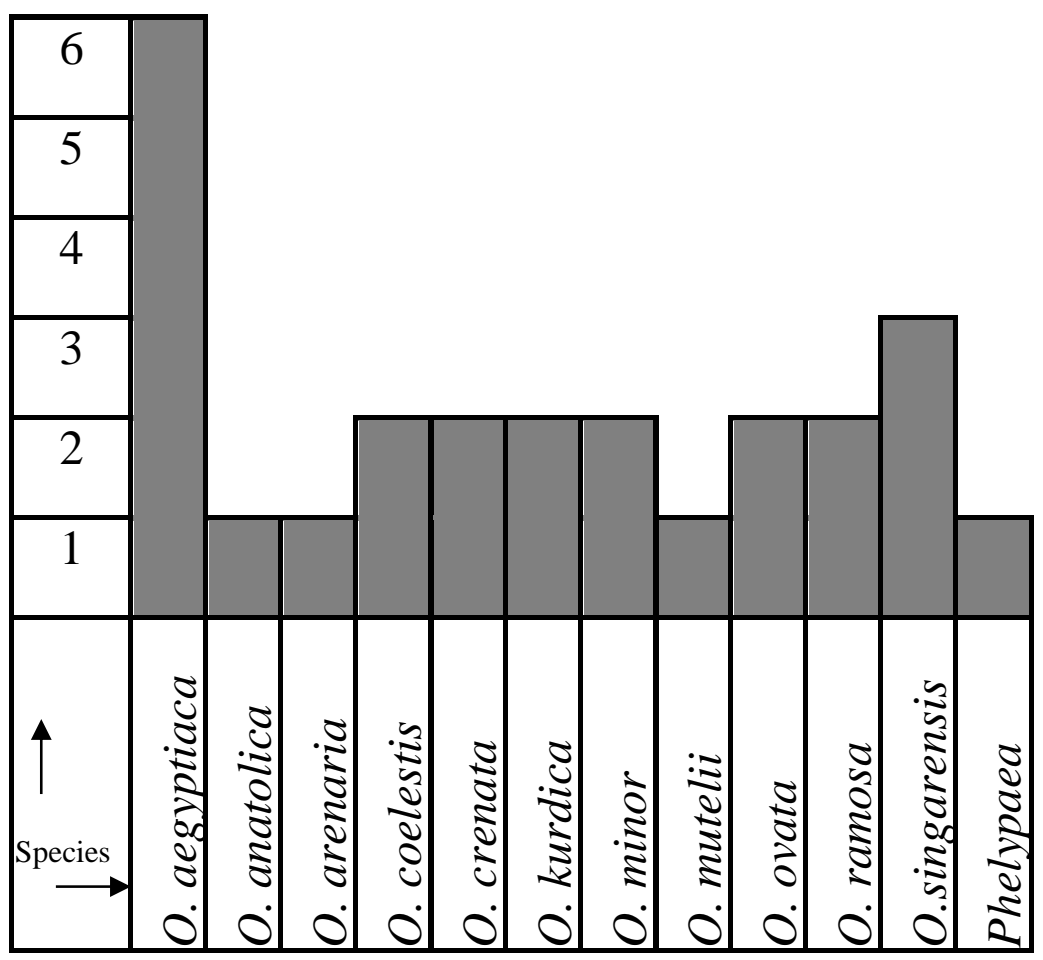

Figure (7) Districts occupied by studied species.

$($ Districts $=$ FPF, FKI, FAR, MSU, MRO, MAM $)$ 


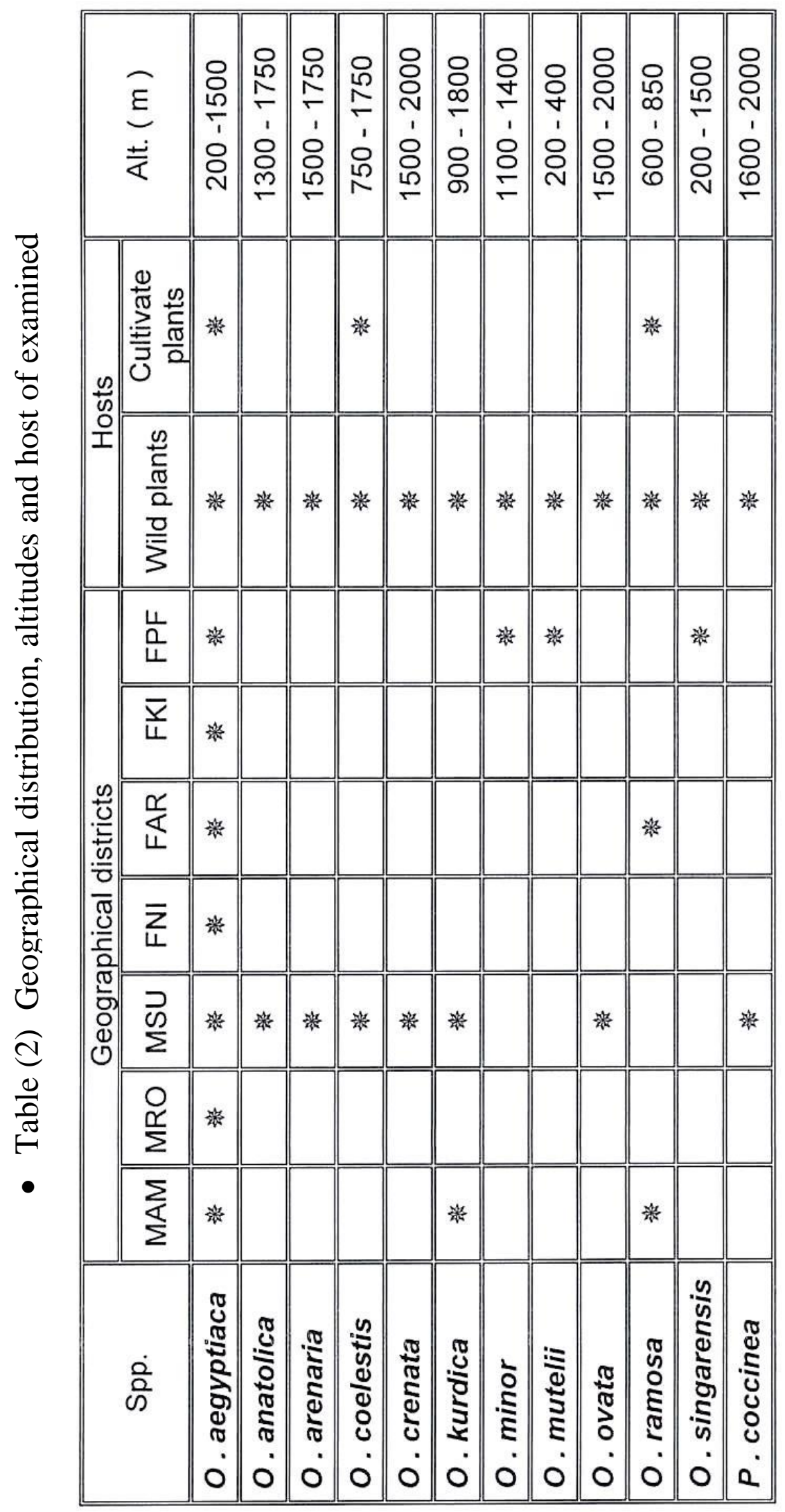




\section{References}

- Al-Katib, Y. M. (1988). Classification of seed Plants. University of Baghdad.

- Al-Mussawi, A. H. (1987), Plant taxonomy. Ministry of higher education and scientific research, Baghdad University.

- Al-Rawi, A. (1964). Wild Plants of Iraq with their distribution, the Ch. Bull. 14, Dir. Gem. Agriculture, Res., Proj. Ministry of Agriculture Government Press. P: 148.

- Blackelock, R. A. (1949). The Rustam Herbarium, Iraqi Systematic list (continued), part 4. Kew Bull. 3 pp: 441-444.

- Davis, P. H. ; Edmondson, J. R. and Mill, R. R. (1982). Flora of Turkey. The University Press. Edinburgh. vol. 7. pp: 1-23.

- Faris, Y. S. (1983). The vascular Plants of Pirramagrun mountain. (MSc. thesis). Salahiddin University. College of science. p. 90.

- Guest, E. R. (1966). Flora of Iraq. Ministry of Agriculture Republic of Iraq. vol. 1.

- Handle Mazzetti, H. F. (1910). Die Vegetation's serhaltnisse von Mesopamien und Kurdistan. pp: 406-407.

- Khalaf, M. K. (1980). The vascular plants of Jabal Singar. Baghdad University. MSc. thesis. P: 125.

- Lawrence, G. H. M. (1951). Taxonomy of Vascular Planets. The Macmillan Company, Newyork. pp: 702-703.

- Parsa, A. (1949). Flora del, Iran. publication du Ministere del education Museum. D’Histoire Nuturelle de Teheran. voll. 4. pp: 486 -519.

- Post, G. E. (1933). Flora of Syria, Palestine and Sinai, American press. Beirut. vol. 2. pp: $310-316$.

- Rechinger, K. H. (1964). Flora Lowland of Iraq. Weinheim Verlag von j. Cramer, Newyork, N. Y. Hafner publishing Co. pp: 551-554.

- Rechinger, K. H. (1964). Flora Iranica, Acadimische Druck -u- Verlag santalt GrazAustria. no. 5. pp:1-24. 
- Ridda, T. j. and Daoud, W. H., (1982). Geographical distribution of wild Vascular Plants of Iraq. National Herbarium of Iraq. Uni. pub. p: 90.

- Thieret, J. W. (1971).The genera of Orobanchaceae in the Southeastern United States. J. Arnold Arboritum, 52. pp: 404-413.

- Zohary, M. (1946), The flora of Iraq and its Phytogeographical Subdivision. Iraq Dep. Agriculture Bull. N. 31. Baghdad. pp: 135-136. 